DE

\title{
Accounting Information Systems Implementation and Management Accounting Change
}

\author{
Krister Bredmar, Urban Ask, Elisabeth Frisk
}

School of Business, Economics and Law, University of Gothenburg, Sweden Johan Magnusson

School of Business, Economics and Law, University of Gothenburg, Sweden Norwegian School of Information Technology-NITH, Oslo, Norway

\section{Abstract}

Background: There is an on-going discussion within management accounting research regarding how to work with performance measures. In the process of developing new forms of performance measurement the task of choosing business metrics is central. This process is closely connected to the implementation of IT solutions. Objectives: In order to understand how new performance measurement solutions are implemented and used, it becomes crucial to understand how measures are selected and how new accounting information systems (AIS) are developed and implemented. Methods/approach: The paper builds on the case of an on-going AIS project at a large, public university in Sweden. The empirical material was collected using a semi-action research approach over a two-year period. The majority of the material comes from written documentation and minutes. Results: Even though the implementation of a new Als triggers a change in the management accounting practice, this study shows that this is done in more than one perspective. Conclusions: As the project develops, new priorities and objectives evolve, which in the end shape what management accounting change becomes.

Keywords: AIS implementation; performance measurement; management accounting change

JEL main category: $M$

JEL classification: M1, M15

Paper type: Research article

Received: 29, November, 2013

Accepted: 2, April, 2014

Citation: Bredmar, K., Ask, U., Frisk, E., Magnusson, J. (2014), "Accounting Information Systems Implementation and Management Accounting Change", Business Systems Research, Vol. 5, No. 2, pp. 125-138.

DOI: 10.2478/bsrj-2014-0015

Acknowledgment: We would like to express our sincere thanks to the Marianne and Marcus Wallenberg Foundation and the Söderberg Foundation for the monetary support necessary in writing this paper. 


\section{Introduction}

For some time, there has been an extensive discussion within management accounting research about how to work with measures in a new way. This debate has its roots in the relevance lost debate that started 30 years ago. Today this debate has come to focus on how to measure and manage performance in different ways. In the centre of the process of developing new forms of performance measurement is the task of choosing business metrics. This is a process or task that is closely connected to the IT solution an organization chooses to use. In a modern context that solution often connects wider system thinking into one larger Enterprise System. In order to understand how new performance measurement solutions are implemented and used, it also becomes crucial to understand how the measures are selected and how new enterprise systems are developed. This is important in order to understand the context in which performance indicators are effective.

\section{IT development projects and management accounting change}

In IT development projects there is usually a well-defined project plan and clear goals on what to implement and who should participate. There are numerous lists on how to run a successful IT project, and it is not unusual that a normative, almost instrumental, perspective dominates an implementation project. But, in the end, this highly structured way of working is primarily about the needs and wishes of the people in the organization. The way different actors in the project work together and the way decisions are made are of great importance, while the way communication and coordination is managed is of even greater importance. There is also a need to handle different kinds of knowledge barriers or challenges, especially those associated with using the systems. Altogether, an IT project is like a coin; it has two sides, one about the configuration and the system itself and one about how the system is used by the people in the organization. These two dimensions need to be addressed in order to successfully run an IT project.

The task of working with management accounting issues is to a large extent a practice that is driven by routines and rules. There are instructions about how to do the budget, what calculation is needed to set a price and what measures an operation should be evaluated by. But in an day to day operation, managers also need to understand what is going on and how the reports should be understood (Bredmar, 2012). A traditional approach, the contingency- style, is that the management accounting function should fit the environment and be a part of the configuration of the organizational system. By saying that, there is also a notion that management accounting change is brought about by managers' new information requirements. Management accounting change then becomes a question of how the formal systems should be configured and, at the same time, what needs, formal and informal, the manager has. Even though change is taking place, management accounting is still a practice that to a large extent is based on routines and rules.

To understand the interaction between an IT project and management accounting change the socio-technical concept could be used. This view is based on an idea that the technical systems and the social systems need to be studied together in order to understand how an organization undergoes change. Even though these two systems are independent of each other, they are correlated, and they are co-producers of an organizations outcome. An IT project is not only a technical challenge but also a project dependent on human and organizational circumstances. Implementation then becomes a social process as well as a technical one. By integrating these two perspectives, performance can improve. A more comprehensive picture is then painted where complex actor networks are 
emerging and heterogeneous networks of IT supported organizational processes are formatted. Consequently, socio-technical theories can provide a better understanding of what is going on in an organization undergoing change through the implementation of new technologies.

\section{Research objective}

In order to grasp the recent debate about new forms of performance measures there is a need to understand how measures are developed and defined, how AIS projects are run and implemented and how management accounting change is conducted formally and informally. This paper seeks to understand that through the help of socio-technical theories. The quest for better performance measures is not only about the best software or the best management accounting practices, but rather about understanding how they best complement each other. The empirical material for this paper comes from an on-going AIS project at a large Swedish university. The focus for this paper is on how performance indicators are developed and defined and which implications this process has had on the larger AIS project. There is also an interest in in how this search for performance indicators has changed management accounting practice. In the next section, a theoretical outline is presented followed by a methodology section. Then, the empirical material is presented followed by a discussion and conclusions.

\section{Literature review}

Even though the interest in performance measurement and management has renewed since the early 1990's and the relevance lost debate, the ideas are by no means new ideas in themselves. During the mid-1950, several books and articles with substantial contributions to the field were published. Drucker (1954) discussed a balanced set of measures including areas such as marketing, innovation and attitudes to mention a few. Argyris (1952) was dealing with the ambition to measure and quantify an operation, and Ridgway (1956) was expressing concerns about how performance measurement was used. In recent years, however, no single author has contributed and been cited as much as Robert $S$ Kaplan within the field of performance measurement in general and when it comes to a balanced set of performance measures in particular (Kaplan, Norton, 1992). His and Norton's publications on a balanced performance measurement system have been the departing point for a vast research output among management accounting researchers all over the world. This makes the performance measurement and management area an interesting field to study and explore even more.

\section{Performance measurement research}

Over the years, research within the field of performance measurement has connected the concept and ideas to several additional fields. There is a natural connection to general concepts like management, strategy and systems, but also to areas such as productivity, efficiency, outcomes and information in general (Neely, 2005). There is also an interest in benchmarking, implementations and models, which has a natural junction to performance measurement (Taticchi, Tonelli, Cagnazzo, 2010). Even though different scholars have contributed to the understanding of what performance measurement is or is not over the years, there still seems to be a need to identify problems, propose frameworks and verify theories in different empirical settings (Neely, 2005). Yet another important area is how different systems handling performance measurement are designed and implemented (Neely et al., 1997). There is a natural way of understanding performance measurement in relation to several other areas, and it is also natural to talk about the development and design 
of different systems, but in a way it all comes down to management issues in general and management accounting and control tasks in particular.

Designing, developing and implementing a new system, several different aspects need to be understood. From its simplest description a system is just a technical and/or mechanical device that is installed into an organisation. Then, there is only a need to train employees and get the machine running. But, in many cases, information systems is more about how they are used and in what ways they can contribute to a competitive advantage (Rackoff, Wiseman, Ullrich, 1985). A common way of understanding successful implementation is that it needs top management support and that the employees need training (Hwang, Lin, Lin, 2012). Many models of system implementation describe different phases and steps. One such a model has been developed by Markus and Tanis (2000).In the first phase, a business case and the solution constraints are decided. In the second phase, the project itself is configured and rolled out, and in the next phase bugs are eliminated and the system is getting to normal operations. In a final fourth phase, the system is maintained and supported and in the long run updated. In models such as this, the system design and implementation is done in a fairly normative and controlled fashion.

\section{Implementing systems}

In many cases, implementing a system and getting it up and running is not enough, however. It needs to be a part of the organisation's competitive edge (Alter, 1999). This can also be described through a form of system development model (Soh, Markus, 1995). In this model, three processes take the IT expenditure all the way through to organisational performance. In the first process, IT costs become IT assets, and in a second process, the actual use in the organisation is taking place. In a third process, a competitive position is established and the impact of the IT solution is generating organisational performance. Altogether there are several different critical areas that need to be monitored. Nah, Lau and Kuang (2001), for example, define eleven critical factors determining ERP implementation success. These follow Markus and Tanis' (2000) process model. It is particularly interesting that factors such as effective communication and determining project champions are crucial in the first charting phase. In the project phase, it is important to develop a change management program and culture, and in the third phase, it is more about monitoring and evaluating performance. In many ways, the models we use are simple descriptions of something much more complex, and the model makes it possible to grasp and act upon the understanding that the model gives. But at the same time, the model can hardly incorporate all aspects of a much more complex and disparate reality in many organisations.

From another point of view, the implementation of a system is also about a change in the way an organisation works. This change can be described as "the need for management accounting systems to change to support managers' new information requirements." (Baines, Langfield-Smith, 2003). Changes in the organizations design, which in the long run lead to a change in organizational performance, is brought about by changes in strategy, changes in the competitive environment, and most interesting for this paper, changes in technology. However, Baines and Langfield-Smith's work points to the fact that a change in organizational factors more or less comes from a change in strategy, even though there is a relation for example between greater use of advanced management accounting techniques have great reliance on non-financial management accounting information. But management control systems can also be seen as a tool for delivering information to operating managers. By doing so, the focus and use of 
advanced management accounting techniques have changed, leading to an integration of operations and strategic priorities (Chenhall, Euske, 2007). A change in the way information is used, through new technology, is in a way also a change in how the organization works e.g. What the information utilises and how they use the information.

\section{Management accounting and change}

Even though the intention sometimes is to make more vast changes, the use of accounting information could rather be seen as a way of smoothing organizational frictions (Lukka, 2007). Changes can then be seen as the implementation of a certain management accounting technique, for example $A B C$ or advanced performance measurement systems. In many cases, however, the change is rather about changing how things should be done, the rules, and understanding how things informally are done, the routines. In addition, there are also institutions where common assumptions, socially constructed, lead actors in an organisation when it comes to activities and relationships (Burns, Scapens, 2000). Altogether, these three concepts helps to understand how a formal change in the management accounting techniques also has effects on the informal ways of working in the organisation. In this way, there can be both stability and change when management accounting rules and routines are changed (Lukka, 2007). "Not only can formal rules legitimate the existence of an organisation, while allowing informal routines to remain intact, but informal routines can also act as the 'protecting' device, legitimating the existing formal rule systems and shielding them from pressures for change." (Lukka, 2007). It is then interesting to try to understand how formal changes are done when it comes to management accounting and how informal routines protect the organization from change.

It is then important to understand that change can both be about changes in technology where organizational change follows, or organizational and technical changes can be undertaken at the same time (Robey, Ross, Boudreau, 2002). In addition to this perspective, there is also a possibility to look at change as a social process, which then forms a socio-technical process of change. "Consequently, it can be argued that many organizational impacts only remain unanticipated, because systems developers are reluctant to tackle the human and organizational aspects of IT projects. Systems development projects have typically been viewed as exercises in technical change, rather than socio-technical change ..." (Doherty, King, 2005). Compared to a standard model, a socio-technical approach is seen as an on-going social process rather than just launching the technical implementation in one shot. Instead of treating the effects as direct and immediate, the technological effects are indirect and involve different time scales (Kling, Lamb, 1999). It is also clear that instead of having an expert who leads the change project, the expert needs to be a co-learner, contributing to the change while learning himself (Trist, 1981). In order to get the change process working, both the organisational dimension and the technical one need to be understood.

\section{Resistance to change and organizational support}

From another perspective, change sometimes also brings about resistance, and several barriers could be identified. Cobb. Helliar and Innes (1995), for example, describe how different forces such as motivators, catalysts and facilities in different forms can shape potential for change. Through the leaders in the organization, these potentials then become actual change in the organization. But there is also a risk that the potential for change runs into barriers for change, which then makes the potential "bounce off" and does not become an actual change. When change is 
taking place there is also a possibility that the change itself becomes a momentum for additional change, which then becomes a form of on-going process. The barriers could for example be different perceptions of priority, the attitudes among staff and their turnover, to name a few. The influencing forces of change could be both positive, they shape potential for change, and negative, they become barriers for change (Kasurinen, 2002). Consequently, it becomes important to both identify and work with the potentials for change and the barriers, in order for a change to happen.

When different technical solutions are in place it becomes important to support and work with a sponsorship process, which makes managers act in accordance with the change, and an education process, which advocates the merits in the change (Argyris, Kaplan, 1994). In addition, and along the same line, there is also a need to create an internal commitment, which should make it easier to overcome barriers and different threats to change. This process primarily involves motivation and support for individual action in the organization, actions in line with the change (Argyris, 1990). Behavioural and organizational variables are central for change to come about (Shields, 1995). Some examples are top management support, training, ownership of resources and specially canned software. There is also a risk that previously working structures become resistance and barriers, which then hinder change to take place. In a way there is a change challenge prior to the technical implementation and then other challenges once the technical solution is in place.

In general, different typologies could be identified in the technical level change in management accounting. Sulaiman and Mitchell (2005) define and describe five different forms of change arguments and logics, which could be described as typologies. The first form is named "addition" where management accounting techniques new to the organisation are introduced. They could also be an extension of the existing techniques. In a second category, "replacement", the new technique replaces the old or existing management accounting system. In the next typology the output from the system is modified, named "output modification". The fourth form or typology is a change that modifies the operations of the management accounting system, "operational modification". And the last typology, "reduction", is a form of change where no new system or technique is introduced and the old system is removed. Altogether, this typology of technical change levels in management accounting systems helps to form useful categories helping to identify and understand change efforts.

Even though much has been written about performance measurement in general, not much has been published on how to choose business metrics, for example. This is almost taken for granted, and still it is a key task for implementing new management accounting ideas and techniques. There have been studies showing that business metrics need to be changed and more or less dynamic (Henri, 2010), but still how have they been chosen and what role do they play in a management accounting and technical change? While this paper is focused on management accounting change, information systems implementation and sociotechnical theories, the operationalization of working with performance measures will be about how these measures and metrics are chosen.

\section{Method}

Selected case

The empirical material is based on one larger case, which was selected through a convenience sample. This study is based on material from a project that a large Swedish university was working with focusing on a management information system. 
Through different expert functions, the authors were able to follow the project at close range and also supported the project managers with second opinions, comments and sometimes also direct suggestions. From time to time, the authors were also part of shorter project phases, evaluating different solutions and supervising project assistants. It was a project that was promoted from the top management level and run all the way through deans down to local administrations and department managers. Even though the top management first brought about the needs of a new management information system, the focus and aim of the project was centred on the middle management and their work routines. The university itself could be described as a traditional European university with an equally large focus on teaching and research. It comes out on top in several rankings and has a high accreditation standard. Furthermore, the middle management works with a traditional structure and rules and routines resemble other universities.

\section{Collecting the empirical material}

The empirical material was collected over a two-year period starting in the autumn of 2011 when the project was launched. From time to time, one or more authors were participating in meetings and informal discussions with the project team and management. In addition to this growing understanding during the project, relevant project documentations and minutes have also formed the empirical material. In addition to this, semi-structured interviews were done with selected members of the project organisation. Even though the authors from time to time have been working closely to the project, the ambition is not to present this study as an action research method or study, but rather as a descriptive example of how this kind of project can be understood.

\section{Analysing case- and action-research material}

In the analysis of the empirical material a conventional case study method was used and the findings were structured in accordance with that. Even though the ambition behind the method has not been to do an action research project, there are several resemblances with action research. From one point of view, action research is a project where researchers are involved with the members of an organization over a matter that is of concern to them (Eden, Huxham, 1996). In action research, focus is on the setting, which is also an important factor for understanding change in this study. There is also a tension between producing new theory through a research project and producing understanding that could be used in a practical setting. In this study, it has been important to try to contribute to existing theory, but also to develop an understanding that could be applied to practice. In the process of using an action research inspired method, it has been important for us to try to explore the "data" rather than collecting it in a classical sense, which is in line with Eden and Huxham's (1996) reasoning. One important benefit from doing an action research inspired project is the ability to triangulate data, and by doing so giving a more just presentation. As presented earlier, even though this has not been a pure action research project, it has been inspired by the method and its benefits in many ways.

\section{Results}

The university is currently working with its profile for the upcoming years, focusing on how they should be organized in 2020. This comes from an escalating need to sharpen a profile and to monitor how resources are used in the mission to educate research and interact with the community. It is also important to form a coherent, decentralized management structure with high quality output altogether packaged 
in a modern form. From a national perspective, the department of education has focused on promoting strategic profile work with an increased autonomy. With this also comes the ability to define scopes and aims and how the management control function should be designed. As a consequence, lower level managers and their strategic responsibility have come to play a crucial part in the reorganisation of the university operation.

\section{AIS project}

In the project instructions for the AIS project there was a clear and sharp description of the need for better information for lower level managers. The project instructions state, "At the University of XXXXX, we currently have problems to grasp and thus understand our operations. The required information is not easily accessible: it is based on uncertain data, different systems and deficiencies in data management. This makes it difficult for the department heads and other managers to make rational and informed decisions. Also follow-up is complicated, extremely time-consuming." This was one of the major aims with the project, to supply relevant management information and decision support and increase the lower level managers' ability to make decisions and act in a strategic, coherent way. The information should be easy to access, have a high quality, support management control and an increased ability to evaluate if goals are met.

There was also a clear project plan with three phases. In the first phase, development and preparations were done, which had a time period of eight months. In this phase, the focus was on modelling different concepts and ideas, forming user-groups and defining strategies associated to the group. In this phase it was also important to define business metrics/ performance indicators, and there was an intention to limit the number of indicators to 4-8 for the higher-level management team. In the second phase, running over six months, there was a focus on implementation where different software specifications were developed, data connections with previous systems were analysed, an adjustment of data storage needs and a limited number of reports, 4-8, were to be defined. In the final phase, the ambition was to get the system running and established within the organisation. In this one-year phase, there was an interest in evaluating the function of the management information system and also to define the continued support needs and establish the long run strategic needs. Altogether, the project plan resembles similar project plans with a clear timetable and well-defined goals and tasks. The most interesting phase for this study is the first one where the performance indicators were defined, and the rest of the results section will describe this.

\section{Ending the first phase}

In the first phase, one of the most important parts was to develop and design performance indicators, which also is the focus of this study. The first phase was reported and in a way ended in April 2012, which was a bit ahead of the original plan. The overall impression from the first phase was that the organisation was genuinely interested in the project and confirmed the need for a project like this. There were several more general conclusions that were drawn from the first phase. During this period, several focus areas had been defined, which then formed the base for performance indicators, which all together should be few, especially at an aggregated management level. In addition to this, there was a need to develop more specific performance measures and indicators that were unique for each department and presented as a palette of measures and indicators. One of the most important measures was student satisfaction, but it was necessary to develop methods and structured information to grasp this. Along the measures it was also 
concluded that it is important to establish target levels for the measures in order to follow the progression, especially on department level. These indicators should have a close connection to strategic aims. At this stage, it was also important to support lower-level managers so that these measures were used to monitor strategic actions in the daily operations, which might need some additional analysis. In addition to department managers, administrators and the top-level management teams, other internal stakeholders were identified, who needed to be able to monitor what was happening in the operations. They needed to be able to gather information from different sources to get a broader picture. Altogether the management information system should be built on a platform, which would secure quality and stability.

One important area in the first phase was to secure that the IT solution really supported the needs in the organisation in the long run, so that there was a clear and strong connection between the need and the IT support. So the needs were analysed and one of the tasks was to evaluate different measures and indicators used at other universities. This was presented in a list where 400 indicators and measures were compiled from about 20 sources. One initial conclusion was that there was a wide dispersion of measures and indicators, and to be able to work with the list and shorten it there was a need to analyse how they meet different criteria relevant for a department manager at the university. After working with the list and consulting different experts, the list was shortened to include 48 measures and indicators. These were then presented to a reference group during a workshop, and they then summarised their interest, e.g. the department managers' interest, into five focus areas. These were 1] research and publication, 2] student satisfaction, 3] education and resources, 4] employees and 5] financial status. The information sources were also targeted, and the project team compiled a list of more then 25 different data sources. This would be the core for the performance measures design and development. In the next step, six workshops were arranged with close to 50 representatives from different departments. This resulted in a form of informationmodel where three important information areas were connected: education, employees and organisation.

\section{Re-shaping the project}

The project report on phase one continued to discuss and analyse how to handle different aspects of such vast information. This was however, so far so good. At this stage there were two more dominant actors who in a way "dictated" what was to be decided on and how the next step should be done. The first one was a female manager $(K X)$ working within the organisation and the second one was a male consultant $(K Y)$ hired for the project. $K X$ had an important role in the first phase working with the workshops forming the 48 measures/indicators list. Later on in the next project phase, $\mathrm{KY}$ took more of a responsibility for the measures list and shortened it to include 15 measures. He wanted to have a simpler output, which could be worked with and integrated in Excel. In this phase, there was also some workshops and comments from department managers. In a way a feeling was growing that the indicators themselves were not as important as the larger information integration. During this period the overall project manager also left the project.

One important additional task for the project team was to select a vendor and work with the configuration of reports and integration of information sources. There were four software platforms that were interesting, which also were included in the evaluation. These were SAP Business Objects, IBM Cognos, Oracle, Microsoft and SAS Institute. They were all evaluated with the help of Gartners information. An evaluation model were defined and used to evaluate the different solutions. Two of 
the solutions were more attractive and interesting for the university, Microsoft and Oracle, and the project team decided to recommend Microsoft's solution. Since the reports, the information integration and in the end the performance measures are the products of the chosen solution, it was important to evaluate the vendors and platforms in a detailed way.

At this later phase of the project, a new project management was selected and the once grand project became smaller. Several of the early goals, aligning the project with the 2020 vision for the university for example, were not that important anymore. The project team was cut in size and several parts of the larger project were put on hold. It became more and more important to integrate new systems into the old ones and to modify the existing software solutions. The initial need for better information was not that crucial anymore and a feasible solution was talked about more frequently. The decision power over the project resources were redirected to higher-level managers and the interaction with middle management stopped. Different forms of evaluations and reports on the progress and conclusions were written, and in general, the project, once an open and collaborative project, became a closed, high-level managed project. This development came about just before the entire project was supposed to be implemented. A once offensive and future focused project became a modification of already existing management accounting systems and practice.

\section{Discussion}

When searching for a common ground for understanding how AIS projects are implemented and if/how it changes management accounting practice, especially with a focus on performance metrics and indicators, one can start with how the project itself is organised and run. The studied project has support from the highest management levels and was in a way started there. It has enough founding and internal staff. All the way throughout the project, managers and experts have been involved and have been able to influence decisions and directions. From time to time different actors have had the lead, more or less responsible for the project and its outcome. In this sense, it is run in a traditional way, with quality staffing and support and resources from top-level managers. It is clear that from several perspectives, it is an AIS project with a clear focus on effectiveness and increased management utilisation.

\section{Project ambition}

It is also clear that the project has a performance measurement perspective that is important for the organisation, right along the ideas of traditional performance measurement and management intentions. Several different performance perspectives are covered and discussions about how to find, gather and present information from up to 20 sources were discussed. There is a significant interest in combining measures and trying to find new ways of reporting and using information. It became clear when 50 managers and staff attended a workshop where measures and performance management were presented and discussed. In a way, there are at least two phases within the project phases that are interesting to picture. The first phase could be seen as a wishing phase, where almost everything is possible. In a first survey, nearly 400 measures were identified with the help of how other universities were running their performance measurement and management. In a second phase, within the project phases, there was a clearer focus on implementing what was feasible. Now, the project coordinator was narrowing down the amount of measures. From the perspectives studied, this is a performance measurement project, but there are of course several other important dimensions too. 
One important angle for this study, which is harder to describe in a clear way, is if/how management accounting practice has changed. In a way this has to do with the fact that the study is taking place ex-ante the actual change of operations is taking place. The project, even though embedded in the organisation, is still under a planning/implementing phase and it is therefore hard to target actual change in practice. One additional problem is that it is also hard to see what management accounting change is. One example is that it has to do with implementing new management accounting techniques, but at the same time it is much more. From one perspective, it is about rules, routines and institutions, which in a way come closer to this study. There is no new technique per se, even though new information technology has been used, and the longer the project is run the more it seems to be touching on rules and routines in the departments. Change is not planned for but occurring as the AIS project moves forward.

\section{Conclusions}

In a way AIS projects, like the one investigated in this paper, trigger change. In this study, this is not in a way that can be described as new rules or routines, nor is it new management accounting techniques that are implemented. But the ability to package management accounting information in a different way is a form of management accounting change, at least when it comes to how managers and staff at the studied university think about management accounting information. Thinking and acting are two important dimensions of a continuously changing process. Through reading a report and interpreting it, management control actions could be the next step (Bredmar, 2012). Changing rules and routines, and in the long run institutions, begins with how we think and talk and interpret our organisation and operations. The studied AIS project has more or less forced managers and staff to think about and ask for new kinds of performance measures, think about how management accounting information can be gathered and presented, and probably, in the long run, change how they look at the organisation they work in.

\section{Previous research}

There are several conclusions that are in line with findings in previous research. Kasurinen (2002) showed that there was a gap between the original goals and the goals of lower level business unit managers. In a way that is also a conclusion from this study. The initial goals were formulated in a certain way, and in the end lower level managers embraced different goals and ambitions. It was also clear that the ambition behind the project shifted over time, and from the start the project was a strategic, long-term investment that ended up being more of an increased efficiency project. The willingness by senior project staff to implement the project results also shifted when there was extensive support from the beginning but almost no support at the end. Altogether, the goals from the start were changed and at the end the entire project looked different.

In a way AIS projects like this trigger change. But it seems like the ambitions from the beginning was more extensive than it came to be at the end. In the first phase of the project almost 400 measures and indicators were interesting, but in the end the ones in charge of the project settled with a handful. This phenomenon is interesting in itself. At first there was a higher ambition, and in the end the expectations were lowered. Still, there were discussions about how to change the use of performance measures in the organisation, what sources they should be compiled from and who should define lower-level information needs. Something seems to happen between the initial glorious possibilities and the cruel day-to-day work. It is wrong to say that it 
is all because of the computer systems that were analysed, but at the same time they sometimes promise more then they deliver (Bredmar, 2011).

\section{Implemented changes}

It is also clear that at the end senior managers wanted more of a modification change (Sulaiman, Mitchell, 2005) and not change in addition or operations of the management accounting system, which was the initial indication. Among the typologies introduced earlier, the initial ambition was more of a replacement or operational modification change orientation, but as the analysis and project results grew and came into shape, the ambition and change focus moved from replacement to modification. Previous research shows that the easiest form of change is the modification and that the most problematic is when new techniques are introduced or old systems are replaced (Sulaiman, Mitchell, 2005). Our findings support this conclusion. There was a growing need to integrate the new techniques and ideas into the existing systems and by doing so turning the change into organizationally constitutive artefacts (Vaivio, 1999). The ambition in the different phases of the project could be categorised along different typologies, but at the end a modification ambition was the one that was most enduring and interesting for senior management.

In a way AIS projects like this trigger change, but maybe not in the way or form that we usually depicts change. Possibly change is something more elusive, hard to track and describe. Maybe it is only possible to see after a much longer period than this study and project can grasp. Maybe change is occurring and still we do not have the methods and means to understand it. AIS projects like this, which this study is based on, changes the way an organisation looks at management accounting information. AIS system becomes new tools that open opportunities that were not there before. Just the thought of having these opportunities might be a change, a change in the way we think about what we need in order to do management accounting work.

\section{References}

1. Alter, S. (1999). "Information systems: a management perspective", $3^{\text {rd }}$ ed., Reading, Mass: Addison Wesley.

2. Argyris, C. (1952), "The impact of budgets on people", New York: Controllership Foundation.

3. Argyris, C. (1990), "The dilemma of implementing controls: the case of managerial accounting", Accounting, Organizations and Society, Vol. 15, No. 6, pp. 503-511.

4. Argyris, C., Kaplan, R. (1994), "Implementing new knowledge: the case of activitybased costing", Accounting Horizons, Vol. 8, No. 3, pp. 83-105.

5. Baines, A., Langfield-Smith, K. (2003), "Antecedents to management accounting change: a structural equation approach", Accounting, Organizations and Society, Vol. 28, No. 7-8, pp. 675-698.

6. Bredmar, K. (2011), "Performance measurement - does ERP systems measure up?", Problems and Perspectives in Management, Vol. 9, No. 3, pp. 33-41.

7. Bredmar, K. (2012), "The act of interpretation - Accounting reports and management control action", Business Management Dynamics, Vol. 2, No. 4, pp. 30-38.

8. Burns, J., Scapens, R. W. (2000). "Conceptualicing management accounting change: an institutional framework", Management Accounting Research, Vol. 11 , No. 1, pp. 3-25. 
9. Chenhall, R. H., Euske, K. J. (2007), "The role of management control systems in planned organizational change: an analysis of two organizations", Accounting, Organizations and Society, Vol. 32, No. 7-8, pp. 601-637.

10. Cobb, I., Helliar, C., Innes, J. (1995), "Management accounting changes in a bank", Management Accounting Research, Vol. 6, No. 2, pp. 155-175.

11. Doherty, N. F., King, M. (2005), "From technical to socio-technical change: tackling the human and organizational aspects of systems development projects", European Journal of Information Systems, Vol. 14, No. 1, pp. 1-5.

12. Drucker, P. F. (1954). "The practice of management", New York: Harper.

13. Eden, C., Huxham, C. (1996), "Action research for management research", British Journal of Management, Vol. 7, No. 1, pp. 75-86.

14. Henri, J. F. (2010), "The periodic review of performance indicators: an empirical investigation of the dynamism of performance measurement systems", European Accounting Review, Vol. 19, No. 1, pp. 73-96.

15. Hwang, M. I., Lin, C. T., Lin, J. W. (2012), "Organizational factors for successful implementation of information systems: disentangling the effect of top management support and training", Proceedings of the Southern Association for Information Systems Conference, Atlanta, GA, USA, 23-24 March, 2012.

16. Kaplan, R., Norton, D. (1992), "The balanced scorecard - Measures that drive performance", Harvard Business Review, Jan-Feb, pp. 71-79.

17. Kasurinen, T. (2002), "Exploring management accounting change: the case of balanced scorecard implementation", Management Accounting Research, Vol. 13, No. 3, pp. 323-343.

18. Kling, R., Lamb, R. (1999), "IT and organizational change in digital economies: an socio-technical approach", Computers and society, Vol. 29, No. 3, pp. 17-25.

19. Lukka, K. (2007), "Management accounting change and stability: loosely coupled rules and routines in action", Management Accounting Research, Vol. 18, No. 1, pp. 76-101.

20. Markus, M. L., Tanis, C. (2000), "The enterprise system experience - from adoption to success", in R. W. Zmud (ed.), "Framing the domains of IT research: Glimpsing the future through the past", Cincinnati, Pinnaflex Educational Resources, pp. 173207.

21. Nah, F. F. H., Lau, J. L. S., Kuang, J. (2001), "Critical factors for successful implementation of enterprise systems", Business Process Management Journal, Vol. 7, No. 3, pp. 285-296.

22. Neely, A. (2005), "The evolution of performance measurement research", International Journal of Operations \& Productions Management, Vol. 25, No. 12, pp. 1264-1277.

23. Neely, A. et al. (1997), "Designing performance measures: a structured approach", International Journal of Operations \& Productions Management, Vol. 17, No. 11, pp. 1131-1152.

24. Rackoff, N., Wiseman, C., Ullrich, W. A. (1985), "Information systems for competitive advantage: implementation of a planning process", MIS Quarterly, Vol. 9, No. 4, pp. 285-294.

25. Ridgway, V. F. (1956), "Dysfunctional consequences of performance measurements", Administrative Science Quarterly, Vol. 1, No. 2, pp. 240-247.

26. Robey, D., Ross, J. W., Boudreau, M. C. (2002), "Learning to implement enterprise systems: an exploratory study of the dialectics of change", Journal of Management Information Systems, Vol. 19, No. 1, pp. 17-46. 
27. Shields, M. D. (1995), "An empirical analysis of firms' implementation experiences with activity-based costing", Journal of Management Accounting Research, Vol. 7, No. 1, pp. 148-165.

28. Soh, C., Markus, M. L. (1995), "How IT creates business value: a process theory synthesis", Proceedings of the 16th International Conference on Information Systems.

29. Sulaiman, S., Mitchell, F. (2005), "Utilising a typology of management accounting change: an empirical anaysis", Management Accounting Research, Vol. 16, No. 4, pp. 422-437.

30. Taticchi, P., Tonelli, F., Cagnazzo, L. (2010), "Performance measurement and management: a literature review and a research agenda", Measuring business excellence, Vol. 14, No. 1, pp. 4-18.

31. Trist, E. (1981), "The evolution of socio-technical systems: a conceptual framework and an action research program", available at: http://www.sociotech.net/wiki/images/9/94/Evolution_of_socio_technical_system s.pdf (17 July 2014)

32. Vaivio, J. (1999), "Exploring a 'non-financial' management accounting change", Management Accounting Research, Vol. 10, No. 4, pp. 409-437.

\section{About the authors}

Krister Bredmar, PhD, is Assistant Professor of Business Administration at the School of Business, Economics and Law, University of Gothenburg. His research interests include Performance Management and Management Control in general. Author can be contacted at krister.bredmar@gu.se

Urban Ask, PhD, is Associate Professor of Business Administration at the School of Business, Economics and Law, University of Gothenburg. His research interests include Accounting Information Systems, Business Intelligence and Analytics and Interactive Data Visualization. Author can be contacted at urban.ask@handels.gu.se

Elisabeth Frisk, PhD, is Assistant Professor in Business Administration at the School of Business, Economics and Law, University of Gothenburg. Her PhD was in Informatics (Evaluating as Designing: Towards a Balanced IT Investment Approach) and she has a master in Accounting. Her research interests involve Evaluating Information System (IS) Investments, Managing as Designing, Accounting and Control for Sustainability, Business Intelligence and Interactive Data Visualization. Author can be contacted at elisabeth.frisk@handels.gu.se

Johan Magnusson, PhD, is Assistant Professor of Business Administration at the School of Business, Economics and Law, University of Gothenburg and a Visiting Professor at The Norwegian School of Information Technology-NITH in Oslo, Norway. His research interests include IT Governance, Enterprise Systems and Interactive Data Visualization. Author can be contacted at johan.magnusson@handels.gu.se 